\title{
Advances in the management of pectus deformities in children
}

\author{
Natalie Swergold ${ }^{1}$, Prasanna Sridharan ${ }^{2}$, Marios Loukas ${ }^{3,4}$, Ronald S. Chamberlain ${ }^{1,2,5}$ \\ ${ }^{1}$ School of Medicine, Saint George's University, Saint George's, Grenada \\ ${ }^{2}$ Department of Surgery, Saint Barnabas Medical Center, Livingston, USA \\ ${ }^{3}$ Department of Anatomical Sciences, Saint George's University School of Medicine, Saint George's, Grenada \\ ${ }^{4}$ Department of Anatomy, Varmia and Mazuria University, Olsztyn, Poland \\ ${ }^{5}$ Department of Surgery, University of Medicine and Dentistry of New Jersey, Newark, USA \\ Email: nmswergs@gmail.com
}

Received 10 May 2013; revised 12 June 2013; accepted 20 June 2013

Copyright (C) 2013 Natalie Swergold et al. This is an open access article distributed under the Creative Commons Attribution License, which permits unrestricted use, distribution, and reproduction in any medium, provided the original work is properly cited.

\begin{abstract}
Pectus excavatum (PE) and pectus carinatum (PC) are relatively common deformities involving the anterior chest wall, occurring in 1:1000 and 1:1500 live births, respectively. While the etiology remains an enigma, the association of pectus deformities with other skeletal abnormalities suggests that connective tissue disease may play a role in their pathogenesis. Clinical features of these deformities vary with severity, as determined by the Haller index and Backer ratio, but frequently include cardiac and respiratory abnormalities. Importantly, there exist profound psychosocial implications for children afflicted with these deformities, including but not limited to feelings of embarrassment and maladaptive social behaviors. These debilitating characteristics have prompted the development of novel medical and surgical corrective techniques. The correction of pectus deformities reduces the incidence of physiological complications secondary to chest wall malformation, while simultaneously improving body image and psychosocial development in the affected pediatric population. The Ravitch (open) and Nuss (minimally invasive) procedures remain the most frequently employed methods of pectus deformity repair, with no difference in overall complication rates, though individual complication rates vary with treatment. The Nuss procedure is associated with a higher rate of recurrence due to bar migration, hemothorax, and pneumothorax. Postoperative pain management is markedly more difficult in patients who have undergone Nuss repair. Patients undergoing the Ravitch procedure require less postoperative analgesia, but have longer operation times and a larger surgical scar. The cosmetic
\end{abstract}

results of the Nuss procedure and its minimally invasive nature make it preferable to the Ravitch repair. Newer treatment modalities, including the vacuum bell, magnetic mini-mover procedure (3MP), and dynamic compression bracing (DCB) appear promising, and may ultimately provide effective methods of noninvasive repair. However, these modalities suffer from a lack of extensive published evidence, and the limited number of studies currently published fail to adequately define their long-term effectiveness.

Keywords: Chest Wall Deformity; Pectus Excavatum; Pectus Carinatum; Chest Wall Repair

\section{PECTUS EXCAVATUM}

Pectus excavatum (PE) is the most common congenital abnormality of the anterior chest wall, occurring in approximately 1:1000 live births [1]. Morphologically, the deformity is characterized by variable depression of the sternum and lower costal cartilages (Figure 1) [2]. The depression is created by posterior angulation of the body of the sternum and posterior angulation of the costal cartilages to meet the sternum [3]. The deformity is asymmetric in almost $50 \%$ of PE patients, with a deeper concavity on the right side. Deep inspiration commonly accentuates its severity [4].

No specific cause of PE has been identified, but its association with other skeletal abnormalities suggests that connective tissue (CT) disease may play a role in its pathogenesis [2]. Approximately two-thirds of patients with Marfan's syndrome (an autosomal dominant disorder characterized by dislocated eye lenses, long limbs and aortic root dilation) exhibit PE, though the most frequently observed monogenic syndrome associated with 




Figure 1. Pectus excavatum.

$\mathrm{PE}$ is Noonan syndrome (NS), an autosomal dominant disorder caused by mutations in various genes in the RasMAPK (mitogen-activated protein kinase) pathway [5]. NS is associated with a constellation of distinctive facial features in infancy, combined with short stature, congenital heart disease and pectus deformity [6]. When found separately from NS, pectus excavatum may also be associated with scoliosis and congenital heart defects [2]. Current theories of PE pathogenicity include intrauterine pressure alterations, an intrinsic failure of osteogenesis and/or chondrogenesis, rickets, and abnormalities of the diaphragm resulting in posterior traction of the sternum (with some reports of PE occurring after repair of agenesis of the diaphragm or congenital diaphragmatic hernia) $[3,7]$. Biochemical studies have shown abnormalities in the structure of type 2 collagen in costal cartilage, abnormal levels of zinc, magnesium and calcium, and a disturbance of collagen synthesis in patients with pectus deformities [7]. The genetics underlying the condition have yet to be definitively determined. In a pedigree analysis of 34 families with PE children, Creswick et al. identified 14 families which demonstrated autosomal dominant inheritance, 4 showed autosomal recessive inheritance, 6 families exhibited X-linked recessive inheritance, and 10 families displayed multiple inheritance patterns [7].

The severity of the chest wall deformity clinically correlates with a variety of cardiac and pulmonary manifestations. Depression of the anterior chest wall may decrease the volume of the chest and lungs and compress the heart, leading to restrictive and obstructive pulmonary disease, as well as morphological and functional cardiac abnormalities [8]. Sternal depression can restrict the heart directly, resulting in compression of the right ventricle and myocardial ischemia, with subsequent electrocardiographic abnormalities (most often partial right bundle-branch block, right-axis deviation and ST seg- ment depression) $[4,8,9]$. On chest auscultation, a split second heart sound is heard in nearly all patients, and a systolic ejection murmur is present in approximately $50 \%$ of patients due to right ventricular compression by the chest wall and the resulting nearness of the posterior aspect of the sternum and the pulmonary artery $[3,10]$. Displacement and rotation of the heart caused by sternal depression can compress basal blood vessels and the bronchi of the inferior lobe of the left lung, resulting in poor ventilation and impaired drainage of secretions in the affected area, subsequently increasing the risk of pneumonia [8]. Patients with PE often report reduced exercise tolerance, fatigue upon minimal effort and exertional dyspnea [11].

$\mathrm{PE}$ is frequently associated with an asthenic build and a typical posture characterized by thoracic kyphosis, forward-sloping shoulders and a protuberant abdomen [3, 9,10]. Long arms, legs, and fingers, high-arched palate, scoliosis, double jointedness, flexibility, flat feet, childhood myopia, poor healing and easy bruising are also commonly seen in children with PE [7]. Children may occasionally experience palpitations, thought to be secondary to transient arrhythmias and mitral valve prolapse, the latter of which is seen in $25 \%-65 \%$ of cases [3, $12,13]$.

\section{PECTUS CARINATUM}

Pectus carinatum (PC) is the second most common congenital abnormality of the chest wall, occurring in approximately 1:1500 live births [14]. For reasons unknown, the condition is more common in males (4:1) [2]. The deformity is defined as an abnormal overgrowth of the costal cartilages, resulting in protrusion of the sternum and adjacent costal cartilages (Figure 2) [15]. PC is classified as either chondrogladiolar or chondromanubrial based on the prominent region of the sternum. In patients diagnosed with chondrogladiolar PC, the middle

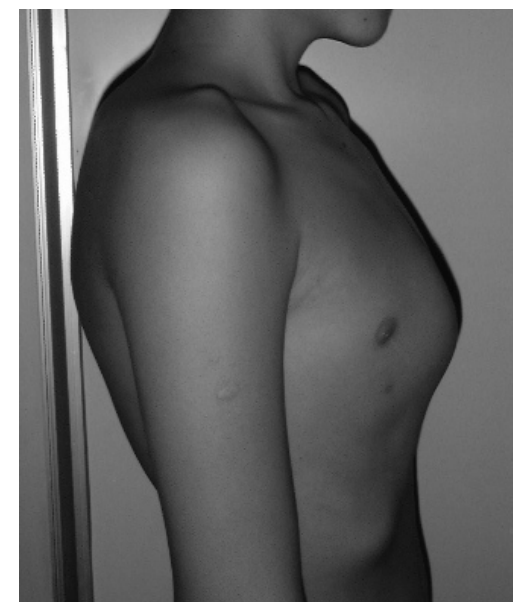

Figure 2. Pectus carinatum. 
and lower portions of the sternum protrude and arch forward, while the costal cartilages are concave and usually symmetrically depressed, accentuating the sternal prominence [16]. The chondromanubrial subtype, also known as Pouter pigeon breast, is far less common, accounting for approximately $5 \%$ of cases [16]. In this subtype, the upper portion of the sternum protrudes anteriorly, and the body of the sternum is deviated posteriorly; anterior deflection of the distal sternum gives the characteristic Z-shape to the sternum on a lateral view [16].

As with PE, a specific cause of PC has yet to be identified, though its association with other skeletal abnormalities suggests that connective tissue disease contributes to its pathogenesis [2]. The most frequently observed monogenic syndrome associated with PC is Marfan's syndrome, a systemic CT disorder caused by mutations in the Fibrillin 1 gene located on the long arm of chromosome 15 [5]. Various congenital anomalies, including sternal fusion defects, costochondral hypoplasia and congenital heart disease are commonly associated with PC $[2,3]$. Most patients with PC are asymptomatic, though patients with severe anomalies may experience pain when lying prone, as well as pain in the area of the protrusion, with or without exercise limitation [2,3].

\section{DIAGNOSIS AND STRATIFICATION OF PECTUS DEFORMITIES}

$\mathrm{PE}$ and PC are diagnosed based on visual examination and clinical findings. The severity of pectus deformity can be measured using the Backer ratio and, more commonly, the Haller index. The former is the ratio between the vertebral body diameter and the distance between the xiphisternal junction and the posterior border of the vertebral body [3]. The Haller index is currently the gold standard for assessing the severity of pectus excavatum, and is based on computed tomography (CT) of the chest $[4,17,18]$. The index is calculated as the ratio between the maximum laterolateral distance and the minimum anteroposterior distance from the anterior portion of the vertebral body to the posterior surface of the sternum. A normal ratio of 2.5 is found in unaffected patients [17], while deformities with a ratio $>3.25$ are considered moderate or severe cases (constituting an indication for surgical correction). Haller et al. reported a mean index of 4.4 in patients who underwent PE repair [4,18].

\section{PSYCHOSOCIAL IMPLICATIONS OF PECTUS DEFORMITY}

There are numerous psychosocial implications associated with a pectus deformity, many of which make repair of the deformity an important consideration (Table 1). Patients with pectus deformities report feelings of embarrassment and shame, lack of self-worth, feelings of inferiority, depressed mood, coyness, timidity and maladaptive social behavior [19]. Cosmetic disfigurement may result in loss of self-esteem, and may affect social behavior, reducing the capacity of afflicted patients to establish an independent identity or begin relationships

Table 1. Summary of studies evaluating psychosocial implications of pectus deformity ${ }^{*}(2000-2012)$.

\begin{tabular}{|c|c|c|}
\hline Study, Year & $\begin{array}{l}\text { Patients } \\
\text { (N) }\end{array}$ & Study Design and Outcomes \\
\hline $\begin{array}{l}\text { Krasopoulos, } \\
2006 \text { [24] }\end{array}$ & 20 & $\begin{array}{l}\text { - Study design: Changes in quality of life and overall satisfaction in young male adults who underwent Nuss repair } \\
\text { assessed. } \\
\text { - Improvements seen in patients' quality of life }(p<0.05) \text { and self-esteem }(p=0.001) \text { post-op. } \\
\text { - Conclusion: Nuss procedure has a positive impact on the physical and psychosocial well-being of children with PE. }\end{array}$ \\
\hline Kelly, 2008 [22] & 555 & $\begin{array}{l}\text { - } \quad \text { Study design: PEEQ administered to patients }(8-21 \text { years of age) before and } 1 \text { year after surgery. } \\
\text { - } \quad \text { Pre-op psychosocial functioning was unrelated to objective PE severity. } \\
\text { - } \quad \text { Body image and physical difficulties component improved post-op }(2.30 \pm 0.62 \text { to } 1.40 \pm 0.42, \text { and } 2.11 \pm 0.82 \\
\text { to } 1.37 \pm 0.44 \text {, respectively). } \\
\text { - } 97 \% \text { of patients thought that surgery improved how their chest looked. } \\
\text { - Conclusion: Surgical repair of PE can improve body image and limitations on physical activity. }\end{array}$ \\
\hline Lam, 2008 [23] & 43 & $\begin{array}{l}\text { - Study design: A retrospective review of patients undergoing Nuss or Ravitch correction of PE was performed } \\
\text { and HRQL assessment was performed using the CHQ-CF87 and PEEQ. } \\
\text { - Nuss patients reported being "less bothered" by the appearance of their chest than did Ravitch patients. } \\
\text { - Compared to age-matched norms, the PE sample showed better scores for family activity domain and worse } \\
\text { scores in mental health, general health perceptions, change in health, bodily pain, and self-esteem. } \\
\text { - Conclusion: Patients undergoing surgery for PE have similar clinical and HRQL outcomes, but as a group } \\
\text { have poorer HRQL scores than age-matched controls. }\end{array}$ \\
\hline $\mathrm{Ji}, 2011[20]$ & 815 & $\begin{array}{l}\text { - Study design: Socio-demographics and CBCL scores were compared for PE patients and controls. } \\
\text { - } \quad \text { PE children displayed higher prevalence of psychosocial problems in the different scales of the CBCL } \\
\text { questionnaire such as "withdrawn", "anxious/depressed", "social problems" and "total problems". } \\
\text { - Age, severity of malformation, and being teased about PE were associated with patients' psychosocial problems. } \\
\text { - Conclusion: Children with PE have more psychosocial problems than children from the general population. }\end{array}$ \\
\hline
\end{tabular}

Abbreviations: $\mathrm{PE}=$ Pectus Excavatum; $\mathrm{CBCL}=$ Achenbach Child Behavior Checklist; $\mathrm{CHQ}-\mathrm{CF} 87=$ Child Health Questionnaire; PEEQ = Pectus Excavatum Evaluation Questionnaire; HRQL = Health-Related Quality-of-Life. 
with persons of the opposite sex [20]. The degree of suffering in patients with $\mathrm{PC}$ may be greater than those with $\mathrm{PE}$, as the former is poorly concealed by clothing [19]. In a study conducted by $\mathrm{Ji}$ et al. analyzing 337 children between 6 years and 16 years with PE, dissatisfaction and being teased about pectus deformity were major motivating factors for treatment, with nearly half of all patients admitting that they had tried hard to avoid exposing their chest in public places, and approximately one quarter reporting that they had been teased about their chest deformity "often or sometimes" by their peers [20]. The study showed an increasing prevalence of psychosocial difficulties with increasing age specifically in patients who do not undergo surgery [20]. Treatment of severe deformities may serve to significantly improve patients' body image and positively influence their psychosocial development.

\section{INDICATIONS FOR THE TREATMENT OF PECTUS DEFORMITY}

While there are currently no consensus guidelines describing relative and absolute contraindications to pectus repair, contraindications to surgery should always be considered when evaluating a patient for surgical repair of chest wall deformity. Jaroszewski et al. have proposed that referral to a pediatric surgeon for consultation should occur when a patient demonstrates any of the following criteria: symptomatic pectus deformity, progression of the deformity, paradoxical movement of the chest wall with deep inspiration, Haller index $>3.0$, cardiac compression or displacement, pulmonary compression, abnormal pulmonary function studies showing restrictive lung disease, mitral valve prolapse, any cardiac pathology secondary to compression of the heart, history of failed previous repair, abnormal cardiopulmonary testing, or significant body image disturbance [12]. In a review by R.E. Kelly et al., these authors defined the indications for surgical treatment as the presence of two or more of the following: a severe, symptomatic deformity; progression of deformity; paradoxical respiratory chest wall motion; CT scan with a pectus index greater than 3.25 ; cardiac compression/displacement and/or pulmonary compression; pulmonary function studies showing restrictive disease; mitral valve prolapse, bundle branch block, or other cardiac pathology secondary to compression of the heart; or failed previous repair(s) [21]. Despite the fact that Kelly et al. did not explicitly reference poor body image as an indication for repair, body image concerns constitute an important consideration in the pectus deformity patient population. Impairments in psychosocial functioning secondary to poor body image should be explored during the work-up of a pectus deformity pa- tient, as surgical repair of pectus deformity may help to alleviate these concerns $[12,22-24]$. There is currently no data evaluating the effects of regular psychiatric followup with a psychiatrist on alleviating the psychological burden of poor body image in this patient group. Nevertheless, the lack of correlation between the anatomic severity of the deformity on CT and the physical and body image components of the child psychosocial assessment scores ( $r=0.01$ and $r=0.06$, respectively) observed by Kelly et al. suggests that presence of the deformity, regardless of severity, results in body image and psychosocial difficulties worthy of attention [22]. These authors also found that at one year post surgery, patients reported significant reductions in body image concerns $(p<$ $0.0001)$ and in difficulties in physical functioning $(p<$ 0.0001 ), and parents perceived significant improvements in their child's emotional functioning $(p<0.01)$, confirming psychosocial improvements with treatment, independent of the modality employed [22]. Similarly, Krasopoulos et al. have reported a statistically significant improvement in the self-esteem of pectus deformity patients after having undergone reparative surgery $(p=$ 0.001 ) [24]. Steinmann et al. proposed that body image concerns may overshadow those of the presence of physical restrictions when ultimately deciding whether or not to repair pectus deformities, as patients' perceptions of their dysmorphia will ultimately influence the extent of satisfaction with treatment outcomes [25].

\section{OLD TREATMENT MODALITIES}

Pectus deformities were recognized as early as the nineteenth century, with a report of five cases published by Ebstein in 1882 [26]. Treatment was limited to fresh air, breathing exercises, aerobic activities and lateral pressures $[27,28]$. Surgical correction of pectus deformities dates back to the early 1900 s, with corrective techniques proposed by Meyer and Sauerbruch [29,30]. In the decades that followed, Brown, Cook and other surgeons developed novel methods for repair, though their methods failed to gain popularity [31]. Prior to 1949, surgical treatment of pectus deformities was based on resection of the sternum and the deformed cartilages, and dissection of the mediastinal and diaphragmatic attachments. Noninvasive approaches included maintenance of the elevated sternum in the corrected position by external traction using harnesses or other cumbersome devices.

In 1949, Ravitch described a procedure based on resection of deformed cartilages and correction of the sternum by wedge osteotomy in the upper sternal cortex, ultimately giving rise to an operative protocol that was used ubiquitously until the late 90s [10,32-34]. The Ravitch procedure has been shown to provide effective correction of pectus deformity, and is ideal for patients 
who have a combination of PE and PC, significant deformity asymmetry, or extensive defects involving the upper ribs and cartilage [4,12,35]. A prospective study by Krueger et al. found that end-diastolic right ventricular diameter, area and volume all significantly increased after this procedure $(p<0.001, p<0.001$, and $p<0.001$, respectively) [32]. Intraoperative transesophageal echocardiogram has revealed that patients with pectus deformities have a marked right ventricular compression and deformation, which is alleviated by surgical correction [32]. The average estimated increases in end-diastolic right ventricular area and volume after surgical correction were found to be $47 \%$ and $88 \%$, respectively [32]. The left ventricular ejection fraction also increased by an average of $14 \%$ after surgical correction $(p<0.001)$ [32]. Disadvantages to the Ravitch procedure include the need for general anesthesia, and longer operation time [2]. A variety of musculoskeletal and/or vascular factors may contribute to pectus deformity recurrence in patients status post Ravitch procedure (Table 2), with recurrence occurring in $5 \%-11 \%$ of cases [36]. Complications associated with the procedure include wound infection, wound dehiscence, pleural effusion, pneumothorax, and up to $555 \mathrm{~mL}$ of blood loss [2,37,38]. Extensive destruction of the perichondrium and rib growth centers may result in failure of further chest wall development and subsequent pulmonary hypertension, tricuspid regurgitation, and restrictive lung disease [39,40]. Furthermore, despite improvement in postoperative cosmesis, the skin incision utilized in the Ravitch procedure results in a large vertical midline chest wall scar, effectively replacing the original aesthetic concern, the pectus deformity, with a different one $[2,9,15,37,41]$. However, despite these complications, the Ravitch procedure was widely accepted as the gold-standard of treatment until 1998, and continues to be performed by many pediatric surgeons today.

\section{NEWER TREATMENT MODALITIES}

In 1987, Dr. Donald Nuss, a pediatric surgeon at Children's Hospital of The King's Daughters in Norfolk, Virginia, developed a novel minimally invasive technique for the correction of pectus deformity. In 1997, Nuss et al. published their 10-year experience with this technique, which required no cartilage incision, resection or sternal osteotomy, but instead relied on internal bracing made possible by the flexibility and malleability of the costal cartilages $[42,43]$. The limited dissection required for this procedure represented a less invasive approach to corrective repair when compared to other procedures, and is a specific consideration in the pediatric population, given the likelihood of these patients developing lifelong complications secondary to extensive chest wall resection [39]. For this repair, also called a minimally invasive repair of PE (MIRPE), a horizontal passage is created underneath the sternum through two small lateral incisions, and under thoracoscopic guidance, a convex bar is inserted through the passage and then rotated to achieve sternal elevation [41]. A minimally invasive reverse Nuss procedure for the treatment of PC employs a similar procedure, though the bar is placed in front of the sternum and fixed to the ribs in a compressing position [2]. Proposed advantages to the minimally invasive Nuss procedure includes shorter operative times, minimal blood loss of less than $90 \mathrm{~mL}$, immediate postoperative extubation, avoidance of instability of the chest wall, maintenance of chest wall elasticity and absence of a large surgical incision, making the Nuss procedure more suited to address psychosocial issues associated with pectus deformity $[37,41,44,45]$. Disadvantages of this minimally invasive repair includes considerable analgesic requirement, a challenging postoperative course in regards to pain control, increased length of hospitalization, and longer and more severe limitations in activity when compared with the open Ravitch procedure [2,4, $23,45,46]$. A significant reduction in forced vital capacity (FVC) on pulmonary function tests after implantation of the pectus bar has been reported $(p<0.001)$, which is theorized to be due to the transient postoperative functional restriction of respiratory movements of the thorax by the pectus bar [47]. The theory is supported by the work of Castellani et al. which showed that forced vital capacity after implant removal reached normal values, and was not significantly different from preoperative FVC $(p=0.117)$ [47]. Spinal distortion, wound infection, pneumothorax, pleural and pericardial effusion, bar displacement, allergy to the bar, overcorrection in $\mathrm{PE}$ patients leading to PC, bleeding from erosion of costal arteries due to movement of the ribs against the bar resulting in hemothorax, aortic laceration, cardiac arrhythmia, and cardiac perforation have all been reported as operative complications of the Nuss procedure [2,37,41,48-50]. Patients greater than 15 years of age are at higher risk for complications due to the higher force necessary to elevate the sternum to the desired level [41]. Thus, the technique has not been as favorable in the adult population, as decreased chest flexibility in this population predisposes them to higher postoperative complications and residual pain that interferes with a return to normal functional status $[2,10]$. Nevertheless, the minimally invasive nature of the Nuss procedure, the superior cosmetic outcomes, the exceedingly low mortality rate comparable to that of the Ravitch repair, and an overall complication rate similar to that of the Ravitch repair have made the Nuss technique the current preferred modality for surgical repair of pectus deformity until further large-scale prospective randomized studies comparing the two procedures suggest otherwise. 
Table 2. Summary of treatment modalities for pectus deformity.

\begin{tabular}{|c|c|c|c|c|}
\hline Treatment & Description & Advantages & Potential Complications/Disadvantages & Limitations \\
\hline $\begin{array}{l}\text { External } \\
\text { Bracing }\end{array}$ & $\begin{array}{l}\text { Maintenance of the } \\
\text { elevated sternum in } \\
\text { corrected position by } \\
\text { external traction } \\
{[4,10]}\end{array}$ & $\begin{array}{ll}- & \text { No risk of anesthesia }[4,10] \\
- & \text { No risk of a surgery }[4,10]\end{array}$ & $\begin{array}{l}\text { - Requires harnesses or other cumbersome } \\
\text { devices }[4,10]\end{array}$ & - \\
\hline $\begin{array}{l}\text { Ravitch } \\
\text { Procedure }\end{array}$ & $\begin{array}{l}\text { Resection of deformed } \\
\text { cartilages and } \\
\text { correction of sternum } \\
\text { by wedge osteotomy } \\
\text { in upper sternal cortex } \\
{[2,4,9,10,32,35,38]}\end{array}$ & $\begin{array}{l}\text { Increase in } \\
\text { end-diastolic RV } \\
\text { diameter, area, and } \\
\text { volume [32] } \\
\text { Increase in LVEF [32] }\end{array}$ & $\begin{array}{ll}- & \text { Central, large scar [2,41] } \\
- & \text { Longer operation time }[2,37,41] \\
- & \text { Wound infection }[2,23,37,53] \\
- & \text { Wound dehiscence [37] } \\
- & \text { Pneumothorax }[2,53] \\
- & \text { Pulmonary hypertension [39] } \\
- & \text { Tricuspid regurgitation [39] } \\
- & \text { Restrictive lung disease [39] } \\
- & \text { Pericardial effusion with tamponade [53] } \\
- & \text { Deformity recurrence associated with: } \\
- & \text { Inadequate support to sternum and anterior chest, [4] } \\
- & \text { Detachment of sternal perichondrial sheaths without } \\
& \text { adequate reattachment, [4] } \\
- & \text { Injury to perichondrial sheaths while removing } \\
& \text { costal cartilages, [4] } \\
- & \text { Resection of large segments of costal cartilage in } \\
& \text { children while growth plates are active, [4] } \\
- & \text { Disrupting vascularity to lower sternum, [4] } \\
- & \text { Excision of the xiphoid, [4] } \\
- & \text { Insecure approximation of the pectoralis and } \\
& \text { abdominal muscles over the cartilaginous repair [4] }\end{array}$ & \\
\hline $\begin{array}{l}\text { Nuss and } \\
\text { Reverse } \\
\text { Nuss } \\
\text { Procedure }\end{array}$ & $\begin{array}{l}\text { Placement of a convex } \\
\text { metal bar behind } \\
\text { sternum through } \\
\text { pleural cavities } \\
{[2,12]}\end{array}$ & $\begin{array}{ll}- & \text { Minimal blood loss of } \\
& <10 \mathrm{~mL}[4,37] \\
- & \text { Immediate post-op } \\
& \text { extubation [37] } \\
- & \text { Rapid mobilization [37] } \\
- & \text { Shorter operative time } \\
& {[2,37,41,45]} \\
- & \text { Avoidance of chest wall } \\
& \text { instability [41] } \\
- & \text { Maintenance of chest wall } \\
& \text { elasticity [41] } \\
- & \text { Absence of a large surgical } \\
\text { incision[41] }\end{array}$ & $\begin{array}{ll}- & \text { Increased length of hospital stay }[33,38,45] \\
- & \text { Longer/more severe limitations in physical activity } \\
& {[38]} \\
- & \text { Increased duration of post-op chest pain and } \\
& \text { significant analgesic requirements }[10,23,41,45,46] \\
- & \text { Spinal distortion }[49] \\
- & \text { Wound infection }[2,24,41,56] \\
- & \text { Pneumothorax }[2,24,33,37,45,47,50,56] \\
- & \text { Hemothorax }[33,50,56] \\
- & \text { Pleural effusion }[5,19,48,50,53] \\
- & \text { Pericardial effusion }[37,50,51] \\
- & \text { Bar displacement }[2,12,41,45,47,50,50] \\
- & \text { Overcorrection in PE leading to PC }[2,45,56] \\
- & \text { Aortic laceration }[48] \\
- & \text { Arrhythmias }[2,41] \\
- & \text { Cardiac perforation }[4,48] \\
- & \text { Reduction of FVC after bar placement }[47]\end{array}$ & $\begin{array}{l}\text { Patients }>15 \text { years of } \\
\text { age are at higher risk } \\
\text { for complications } \\
\text { [41] }\end{array}$ \\
\hline $\begin{array}{l}\text { Dynamic } \\
\text { Compression } \\
\text { Bracing }\end{array}$ & $\begin{array}{l}\text { Custom-fitted } \\
\text { aluminum brace } \\
\text { assembled to form a } \\
\text { rigid belt that } \\
\text { surrounds the } \\
\text { thoracic wall at the } \\
\text { level of the defect [15] }\end{array}$ & $\begin{array}{ll}- & \text { No risk of anesthesia [15] } \\
- & \text { No visible scar [15] } \\
- & \text { No hospital admission [15] } \\
- & \text { Reduced cost to treat [15] }\end{array}$ & $\begin{array}{ll}- & \text { Skin ulceration }[15] \\
- & \text { Social discomfort }[15] \\
- & \text { Back pain [15] } \\
- & \text { Hematoma [15] } \\
- & \text { Recurrence [15] } \\
- & \text { Pressure necrosis }[15] \\
- & \text { May only remove brace when showering or playing } \\
& \text { sports [15] }\end{array}$ & $\begin{array}{l}\text { Patients with severe } \\
\text { deformities require } \\
\text { higher compression } \\
\text { pressures, resulting } \\
\text { in an increased } \\
\text { complication rate } \\
\text { [15] }\end{array}$ \\
\hline Vacuum Bell & $\begin{array}{l}\text { Suction cup applied to - } \\
\text { chest wall, creating a } \\
\text { vacuum that sucks } \\
\text { deformity outward } \\
{[2,44]}\end{array}$ & $\begin{array}{ll}- & \text { No risk of anesthesia [44] } \\
- & \text { No risk of a major surgical } \\
& \text { procedure [44] } \\
- & \text { No large surgical } \\
& \text { incision [44] }\end{array}$ & $\begin{array}{ll}- & \text { Subcutaneous hematoma [44] } \\
- & \text { Petechial bleeding [44] } \\
- & \text { Dorsalgia and transient paresthesia of upper } \\
& \text { extremities during application [44] } \\
- & \text { Rib fractures [44] } \\
- & \text { No evidence of long-term efficacy }\end{array}$ & $\begin{array}{l}\text { Contraindicated in } \\
\text { O.I., Glisson's } \\
\text { disease, } \\
\text { vasculopathies, } \\
\text { coagulopathies, and } \\
\text { cardiac disorders [44] }\end{array}$ \\
\hline
\end{tabular}


Continued

\begin{tabular}{|c|c|c|c|c|}
\hline $\begin{array}{l}\text { Magnetic } \\
\text { Mini-Mover } \\
\text { Procedure }\end{array}$ & $\begin{array}{l}\text { A magnet implanted in } \\
\text { the retrosternal space - } \\
\text { attracts a magnet in - } \\
\text { an external } \\
\text { brace }[2,51]\end{array}$ & $\begin{array}{l}\text { Reduced treatment cost [51] } \\
\text { No hospital admission [51] } \\
\text { Minimally invasive [51] }\end{array}$ & $\begin{array}{l}\text { Must be used } \geq 30 \mathrm{~min} \text {, twice daily [51] } \\
\text { No evidence of long-term efficacy }\end{array}$ & $\begin{array}{l}\text { Not as effective in } \\
\text { patients who are older, } \\
\text { or in late or } \\
\text { post-pubertal stage, } \\
\text { when costal cartilage } \\
\text { is less compliant [51] }\end{array}$ \\
\hline
\end{tabular}

Abbreviations: PE = Pectus Excavatum; PC = Pectus Carinatum; FVC = Forced Vital Capacity; O.I. = Osteogenesis Imperfecta; RV = Right Ventricular; LVEF $=$ Left Ventricular Ejection Fraction.

Another of the newer treatment modalities utilized in correction of pectus deformities is dynamic compression bracing (DCB). The compression brace is assembled using multiple lightweight aluminum curved segments to obtain a rigid belt that surrounds the thoracic wall at the level of the defect [15]. A cushioned compression plate is attached to the anterior segment of the brace and placed at the level of the protrusion [15]. By pushing the sternum backward, the continuous anterior-posterior chest compression gradually reshapes the chest into a normal contour [15]. An electronic pressure measuring device is attached to the brace, permitting adjustments of the pressure to the desired level, so as to avoid inadvertent pressure necrosis and/or noncompliance due to discomfort [15]. Patients who are compliant with DCB treatment protocol see improvement within five months of treatment, and limited short-term studies suggest that improvements are maintained over time [40]. While there are numerous advantages to DCB, including but not limited to the elimination of the risks of anesthesia and major surgery, a decrease in complication rates, absence of a visible scar, avoidance of hospital admission, and a reduction in the cost of treatment, dynamic compression bracing is not without complications [15]. Skin ulceration, back pain, hematoma, recurrence requiring further compression, slight or moderate skin rash at the site of compression, and social discomfort have all been reported in patients undergoing DCB $[15,40]$.

More recently, the vacuum bell has also been explored as a novel therapeutic option for PE. Treatment is accomplished via a suction cup applied directly to the chest wall, in order to create a vacuum that places outward traction on the chest concavity. A vacuum up to $15 \%$ below atmospheric pressure gradient is created by the patient using a hand pump, and must be used for at least 30 minutes, twice daily, for a minimum of 30 days [44]. The application of the vacuum bell must be performed under careful supervision in children under the age of 10 , as the force of the vacuum can lead to rapid sternal and rib elevation, deforming the chest within minutes [44]. Additional complications associated with this treatment modality include subcutaneous hematoma, petechial bleeding, dorsalgia and transient paresthesia of the upper extremities during the application, and rib fractures, though currently available data indicates that the vacuum bell is relatively well tolerated by both the pediatric and adult population [44]. The vacuum bell is contraindicated in Osteogenesis Imperfecta, Glisson's disease, vasculopathies (e.g. Marfan's syndrome, abdominal aneurysm), coagulopathy and cardiac disorders [44]. This list of contraindications vastly limits the use of vacuum bell therapy, as many of these comorbidities are seen in the pectus deformity patient population. While long-term studies regarding the efficacy of the vacuum bell have yet to be conducted, Hacker et al. proposed that patients with symmetric and mild PE may benefit more than those with asymmetric and deep PE, although there is no data to substantiate this claim [44]. Additionally, limited studies suggest that this method of repair may serve as a means of surgical pretreatment in the future, and that if used intraoperatively, the vacuum bell may facilitate the introduction of the pectus bar into the retrosternal precardiac space during the Nuss repair $[2,44]$.

In 2012, Harrison et al. conducted a study in which magnetic forces were used to gradually remodel PE deformity [51]. The magnetic mini-mover procedure (3MP) requires the use of two magnets, one implanted in the retrosternal space and the other in an external brace [51]. Attraction between the two magnets results in a gradual remodeling of the chest over several months [2]. As per current recommendations, patients should begin 3MP treatment within a year of starting the pubertal growth spurt, continuing until correction is achieved (12 - 24 months on average) and potentially keeping the implant for intermittent treatment, with the implant removed once the growth spurt is complete [51]. Treatment response is directly related to the compliance of the chest wall, which correlates with skeletal maturity [51]. Pectus deformities increase in severity during the growth spurt, indicating increased susceptibility to cartilaginous remodeling during this time [51]. Repair of pectus deformities via $3 \mathrm{MP}$ in patients in the late pubertal and post-pubertal periods becomes increasingly difficult, as the malformed cartilages ossify and the chest wall becomes more rigid [51]. Long-term efficacy of 3MP is yet to be determined, but its cost effectiveness ( $\$ 46,849$ for 3MP vs. $\$ 81,206$ and $\$ 81,022$ for the Nuss and Ravitch procedure, respectively [51]) and minimally invasive nature make it an appealing outpatient option for the management of pectus deformity. 


\section{COMPARISON OF TREATMENT MODALITIES}

Haller et al. reviewed 664 surgical procedures performed for the correction of pectus deformities, and suggested surgery for severe deformity in childhood for the following reasons: to relieve structural compression of the chest and allow normal growth of the thorax; to prevent pulmonary and cardiac dysfunction in adolescents and adults; and to eliminate the cosmetic impact that may discourage a growing child from participating in physical activities [52]. These authors suggested that repair should ideally be performed by the age of $4-6$ years [52]. During this time, it becomes possible to gauge which patients have moderate to severe physical defects, and would thus benefit most from repair. Furthermore, children in this age bracket displayed sufficient emotional maturity to endure a hospital visit without experiencing the psychosocial sequelae observed in adolescents who have undergone hospitalization [52].

Of the numerous surgical techniques used for the repair of pectus deformity (Tables 3 and 4), the two most widely used today are the Ravitch (open) and Nuss (minimally invasive) methods. Nasr et al. performed a systematic review comparing perioperative complication rates of both procedures, and found no significant difference in overall complication rates between the two techniques (OR, 1.75 [95\% CI, $0.62-4.95] ; p=0.30$ ), though specific complications rates did vary based on the procedure utilized [33]. The rate of reoperation seconddary to bar migration or persistent deformity was significantly higher in the Nuss group (OR, 5.68 [95\% CI, $2.51-12.85] ; p=0.0001$ ) [33]. The incidence of he-

Table 3. Summary of studies evaluating treatment modalities for pectus excavatum ${ }^{*}(2000-2012)$.

\begin{tabular}{|c|c|c|c|}
\hline Study, Year & $\begin{array}{l}\text { Patients } \\
\text { (N) }\end{array}$ & $\begin{array}{l}\text { Treatment } \\
\text { Modality }\end{array}$ & Study Design and Outcomes \\
\hline $\begin{array}{l}\text { Fonkalsrud, } \\
2000[38]\end{array}$ & 375 & Ravitch & $\begin{array}{l}\text { - } \quad \text { Study design: Review of patients who underwent Ravitch PE repair } \\
\text { - } \quad \text { Mean LOHS: } 3.1 \text { days } \\
\text { - } \quad \text { FVC increased } 11 \% \text { within } 9 \text { mo. in } 35 \text { patients } \\
\text { - Complications: hypertrophic scar }(\mathrm{N}=35) \text {, atelectasis }(\mathrm{N}=12) \text {, pleural effusion }(\mathrm{N}=13) \text {, recurrent sternal } \\
\text { depression }(\mathrm{N}=5) \text {, pericarditis }(\mathrm{N}=3) \\
\text { - Conclusion: } \mathrm{PE} \text { can be repaired with few complications, short LOHS, and excellent long-term results }\end{array}$ \\
\hline $\begin{array}{l}\text { Fonkalsrud, } \\
2002[45]\end{array}$ & 207 & $\begin{array}{l}\text { Nuss vs. } \\
\text { Ravitch }\end{array}$ & 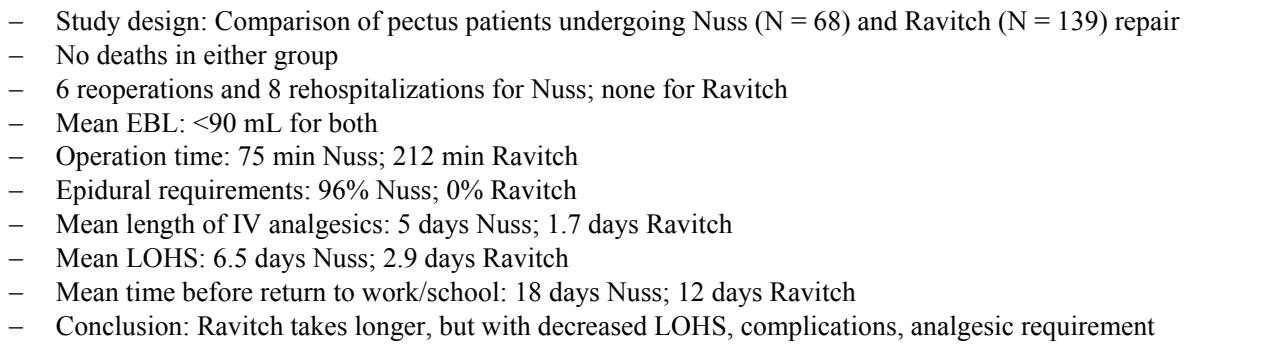 \\
\hline $\begin{array}{l}\text { Mansour, } \\
2003 \text { [57] }\end{array}$ & 77 & Ravitch & $\begin{array}{l}\text { - Study design: Retrospective review of patients who underwent Ravitch repair of PE or PC } \\
\text { - Complications occurred in } 11 \text { patients; } 1 \text { patient required reoperation for PE recurrence } \\
\text { - Mean LOHS }=4 \text { days } \\
\text { - Conclusion: Pectus can be repaired with low morbidity, no mortality, and excellent long-term results. }\end{array}$ \\
\hline $\begin{array}{l}\text { Boehm, } \\
2004 \text { [37] }\end{array}$ & 28 & $\begin{array}{l}\text { Nuss vs. } \\
\text { Ravitch }\end{array}$ & $\begin{array}{l}\text { - Study design: Complications, outcomes, satisfaction evaluated in patients who underwent PE repair } \\
\text { - } \quad \text { Operation times: } 53 \pm 18 \mathrm{~min} \text {. for Nuss; } 125 \pm 6 \mathrm{~min} \text {. for Ravitch } \\
\text { - } \quad \text { Mean EBL: minimal for Nuss; } 380 \pm 175 \mathrm{ml} \text { for Ravitch } \\
\text { - } \quad \text { Intra-op complications: } 0 \text { Nuss; } 2 \text { pleural lacerations in Ravitch group } \\
\text { - } \quad \text { Nuss post-op complications: } 2 \text { pneumothoraces, } 1 \text { pleural effusion, } 1 \text { costal erosion, } 2 \text { bar dislocations, } 1 \\
\text { wound infection requiring bar removal, } 1 \text { hemothorax, } 1 \text { case of PPS } \\
\text { - Ravitch post-op complications: } 1 \text { pneumothorax, } 1 \text { wound infection, } 1 \text { pleural effusion } \\
\text { - Conclusion: Nuss procedure may become method of choice for PE repair. }\end{array}$ \\
\hline $\begin{array}{l}\text { Kim, } \\
2005 \text { [41] }\end{array}$ & 51 & Nuss & $\begin{array}{l}\text { - Study design: Patients who underwent Nuss repair were classified into } 3 \text { groups based on age and outcomes } \\
\text { were retrospectively analyzed. } \\
\text { - } \quad \text { Mean operation time: } 52.0 \pm 22.9 \mathrm{~min}, 80.4 \pm 27.4 \mathrm{~min} \text {, and } 127.3 \pm 44.9 \mathrm{~min} \text { in pediatrics, adolescents, } \\
\text { and adults, respectively }(\mathrm{p}<0.001)^{*} \\
\text { - } \quad \text { Post-op complications: } 11.1 \% \text { of pediatrics; } 58.3 \% \text { of both adolescents and adults }(p=0.002) \\
\text { - Complications requiring reoperation: } 3.7 \% \text { of pediatrics; } 16.6 \% \text { of adolescents; } 41.7 \% \text { of adults }(p=0.001) \\
\text { - Conclusion: Nuss is highly recommended in pediatric PE patients. Select adults for repair carefully. }\end{array}$ \\
\hline
\end{tabular}




\section{Continued}

\begin{tabular}{|c|c|c|}
\hline $\begin{array}{l}\text { Haecker, } \\
2006[44]\end{array}$ & 34 & $\begin{array}{l}\text { Vacuum } \\
\text { Bell }\end{array}$ \\
\hline $\begin{array}{l}\text { Kelly, } \\
2007 \text { [53] }\end{array}$ & 327 & $\begin{array}{l}\text { Nuss vs. } \\
\text { Ravitch }\end{array}$ \\
\hline $\begin{array}{l}\text { Antonoff, } \\
2009 \text { [46] }\end{array}$ & 92 & $\begin{array}{l}\text { Nuss vs. } \\
\text { Ravitch }\end{array}$ \\
\hline $\begin{array}{l}\text { Castellani, } \\
2010 \text { [47] }\end{array}$ & 59 & Nuss \\
\hline
\end{tabular}

Krueger, $2010[32]$ Ravitch

Nasr, 2010 [33]

\section{Kelly,} $2010[50]$
- Study design: A suction cup used to create a vacuum for PE repair.

- After $3 \mathrm{mo}$, an elevation of $>1.5 \mathrm{~cm}$ was seen in 27 patients $(79 \%)$

- After $12 \mathrm{mo}$, the sternum was lifted to a normal level in 5 patients (14.7\%)

- Conclusion: Vacuum bell is another treatment option for PE and may also assist during Nuss repair.

- Study design: Data regarding hospital complications and perioperative pain status-post PE repair were collected at 11 centers

- $\quad 0 \%$ of patients experienced perioperative hemothorax or pericarditis regardless of procedure type

- Wound infection, pneumonia, pneumothorax, and pericardial effusion with tamponade occurred in a larger percentage of Ravitch patients than Nuss patients

- Atelectasis and pleural effusion occurred in a larger percentage of Nuss patients than Ravitch patients

- No overall difference between the two procedures with respect to pain $(\mathrm{p}<0.01)$

- Conclusion: Disproportionate enrollment limited statistical comparison between operation types. There is no overall difference in post-op pain

- Study design: Operative time, LOHS, analgesia, fees, complications noted from PE repairs

- No difference in operative times among groups

- Mean LOHS: 2.2 days Ravitch; 3.9 days Nuss $(p<0.005)$

- Epidural analgesia/PCA requirements: 50\% Ravitch; $100 \%$ Nuss

- Mean charges: \$27,414 Ravitch; \$43,749 (Nuss) $(p<0.05)$

- Complications rate: $14.3 \%$ Ravitch; $35.7 \%$ Nuss

- Conclusion: LOHS, fees, analgesic needs, and complication rate highest in Nuss repair group

- Study design: Pre-op, post-op, post-implant removal spirometry done in patients who underwent Nuss

- Post-Nuss FVC decreased from $91 \%$ of normal to $79 \%$, but increased to $88 \%$ after implant removal

- Conclusion: PE repair resulted in a temporary reduction of FVC which resolved after implant removal

- Study design: TEE performed pre-, intra-, and post-op on patients undergoing Ravitch PE repair.

- EDVD, area, and volume increased post-op $\left(2.4 \pm 0.8 \mathrm{~cm}\right.$ vs. $3.0 \pm 0.9 \mathrm{~cm}, p<0.001 ; 12.5 \pm 5.2 \mathrm{~cm}^{2} \mathrm{vs}$. $18.4 \pm 7.5 \mathrm{~cm}^{2}, p<0.001$; and $21.7 \pm 11.7 \mathrm{~mL}$ vs. $40.8 \pm 23 \mathrm{~mL}, p<0.001$, respectively)

- $\quad$ LVEF increased post-op $(58.4 \% \pm 15 \%$ vs. $66.2 \% \pm 6 \%, \mathrm{p}<0.001)$

- Conclusion: Ravitch repair of PE results in increased end-diastolic RV dimensions and LVEF

- Study design: Statistical analysis of all publications describing Ravitch and Nuss repair of PE

- No difference in overall complication rates (OR, $1.75(0.62-4.95) ; p=0.30)$

- Rate of re-operation higher in Nuss group (OR, $5.68(2.51-12.85) ; p=0.0001)$

- Post-op pneumo- and hemothorax higher in Nuss group (OR, 6.06 [1.57 - 23.48]; $p=0.009$ )

- Time of surgery longer with Ravitch (WMD, $69.94 \min (0.83-139.04) ; p=0.05)$

- No difference in LOHS (WMD, 0.4 days ( -2.05 to 2.86$) ; p=0.75$ )

- No difference in time to ambulation post-op (WMD, 0.33 days [ -0.89 to 0.23$] ; p=0.24$ )

- Conclusion: No differences in overall complications, LOHS, and time to ambulation. Reoperations, post-op hemo- and pneumothorax were higher after Nuss.

- Study design: Review of PE patients who underwent Nuss repair over a 20-year period, with a focus on the technical modifications which have been made during the latter 10 years to increase the safety and success rate of the procedure

- In primary operation patients, bar displacement rate requiring surgical repositioning decreased from $12 \%$ in the first decade to $1 \%$ in the second decade

- Age at operation has shifted from a median age of 6 years (range 1 - 15) during the first 10 years of the study, to 14 years (range 1 - 31) during the last 10 years of the study

- Recurrence of sufficient severity to require reoperation occurred in $1.4 \%$ of primary surgical patients

- Conclusion: The Nuss repair of PE is safe and effective, with a $95.8 \%$ good to excellent result after primary repair

- Study design: Post-implant and post-explant EKG, monthly CXR, and change in pectus severity index assessed in PE patients who used 3MP

- Device failure or poor positioning requiring revision seen in 5 patients

- Severity index improved in patients in early/mid-puberty but not in those with noncompliant chest walls

- $\quad$ Average cost: $\$ 46,859$

- Conclusion: $3 \mathrm{MP}$ is an alternative treatment option for patients in early/mid-puberty with PE.

Abbreviations: 3MP = Mini-Magnet Mover Procedure; FVC = Forced Vital Capacity; PE = Pectus Excavatum; PC = Pectus Carinatum; OR = Odds Ratio; WMD = Weighted Mean Difference; EKG = Electrocardiograms; CXR = Chest X-Ray; FVC = Forced Vital Capacity; PCA = Patient-Controlled Analgesia; $\mathrm{TEE}=$ Transesophageal Echocardiography; LVEF = Left Ventricular Ejection Fraction; CENTRAL = Cochrane Central Register of Controlled Trials; EBL = Estimated Blood Loss; LOHS = Length Of Hospital Stay; PPS = Postpericardiotomy Syndrome; PFT = Pulmonary Function Testing; EDVD = End-Diastolic Ventricular Diameter. ${ }^{*} p$ value: statistical significance, $<0.05 ;{ }^{\dagger} \mathrm{r}$ value: Pearson correlation. 
Table 4. Summary of studies evaluating treatment modalities for pectus carinatum ${ }^{*}(2000-2012)$.

\begin{tabular}{|c|c|c|c|}
\hline Study, Year & $\begin{array}{l}\text { Patients } \\
(\mathrm{N})\end{array}$ & $\begin{array}{l}\text { Treatment } \\
\text { Modality }\end{array}$ & Study Design and Outcomes \\
\hline $\begin{array}{l}\text { Fonkalsrud, } \\
2002[45]\end{array}$ & 207 & $\begin{array}{l}\text { Nuss vs. } \\
\text { Ravitch }\end{array}$ & $\begin{array}{l}\text { - } \quad \text { Study design: Comparison of PC and PE patients undergoing Nuss }(\mathrm{N}=68) \text { and Ravitch }(\mathrm{N}=139) \text { repair } \\
-\quad \text { No deaths in either group } \\
-\quad 6 \text { reoperations and } 8 \text { rehospitalizations for Nuss; none for Ravitch } \\
-\quad \text { Mean EBL: }<90 \mathrm{~mL} \text { for both } \\
-\quad \text { Operation time: } 75 \text { min Nuss; } 212 \text { min Ravitch } \\
-\quad \text { Epidural requirements: } 96 \% \text { Nuss; } 0 \% \text { Ravitch } \\
-\quad \text { Mean length of IV analgesics: } 5 \text { days Nuss; } 1.7 \text { days Ravitch } \\
-\quad \text { Mean LOHS: } 6.5 \text { days Nuss; } 2.9 \text { days Ravitch } \\
-\quad \text { Mean time before return to work/school: } 18 \text { days Nuss; } 12 \text { days Ravitch } \\
-\quad \text { Conclusion: Ravitch takes longer, but with decreased LOHS, complications, and analgesic requirement }\end{array}$ \\
\hline $\begin{array}{l}\text { Mansour, } \\
2003 \text { [57] }\end{array}$ & 77 & Ravitch & $\begin{array}{l}\text { - Study design: Retrospective review of patients who underwent Ravitch repair of PE or PC } \\
\text { - } \quad \text { Complications occurred in } 11 \text { patients; } 1 \text { patient required reoperation for PE recurrence } \\
\text { - Mean LOHS }=4 \text { days } \\
\text { - } \quad \text { Conclusion: PE and PC can be repaired with low morbidity, no mortality, and excellent long-term results. }\end{array}$ \\
\hline $\begin{array}{l}\text { Martinez-Ferro, } \\
2008 \text { [15] }\end{array}$ & 112 & DCB & $\begin{array}{l}\text { - } \quad \text { Study design: Patients with PC treated using DCB and evaluated via double-blinded scale ( } 1-10 \text { points). } \\
-99 \text { of } 112(88.4 \%) \text { had good to excellent results }(7-10 \text { points }) \\
-\quad 13 \text { of } 112(11.6 \%) \text { had poor or failed results }(1-6 \text { points }) \\
\text { - } \quad \text { Starting treatment with }<2.5 \text { PSI avoids skin lesions; patients requiring }>7.5 \text { PSI should not undergo DCB } \\
\text { - } \quad \text { Conclusion: Patients with PC should have a trial of DCB before recommending surgical resection. }\end{array}$ \\
\hline
\end{tabular}

Abbreviations: PSI = Pounds Per Square Inch; PE = Pectus Excavatum; PC = Pectus Carinatum; DCB = Dynamic Compression Bracing; EBL $=$ Estimated Blood Loss; LOHS $=$ Length Of Hospital Stay.

mothorax and pneumothorax was also higher in the Nuss group (OR, 6.06 [1.57 - 23.48]; $p=0.009$ and OR, 5.60 [95\% CI, $1.00-31.33$ ]; $p=0.05$, respectively) [33]. There was no difference between the two procedures with regards to the need for perioperative blood transfusion [33]. The study revealed longer operative times with the Ravitch procedure when compared to the Nuss (Weighted Mean Difference [WMD], 69.94 minutes [95\% CI, 0.83 - 139.04]; $p=0.05$ ), but there was no difference in length of hospital stay (WMD, 0.4 days [95\% CI, -2.05 to 2.86]; $p=0.75$ ) or time to ambulation (WMD, 0.33 days [95\% CI, -0.89 to 0.23 ]; $p=0.24$ ) between both groups [33]. Kelly Jr. et al. performed a prospective multicenter study of management of pectus excavatum by both the open and Nuss procedures and similarly found little difference in overall complication rates within 30 days of operation, but reported a higher incidence of Horner's syndrome, hematoma, stitch abscess, atelectasis, and pleural effusion in the Nuss group, and a higher incidence of pneumothorax, pericardial effusion with tamponade, wound infection, skin rash, and pneumonia in the open repair group (statistical significance not reported) [53]. The absence of a standardized approach to pain management resulted in an inability for Nasr et al. to make direct comparisons of pain-related outcome measures between the two procedures, while Kelly Jr. et al. reported no significant difference between the two procedures with respect to pain within 48 hours after discharge $(p<0.01)[14,33]$. Fonkalsrud et al. found that epidural analgesia was required in 66 of 68 Nuss patients (for an average of 3 days), whereas none of the Ravitch patients received epidural analgesia [45]. Intravenous analgesia was administered for an average of 5 days in Nuss patients and 1.7 days in Ravitch patients (statistical significance not reported) [45]. Lam et al. also documented prolonged use of epidural and/or opioid therapy for pain control in the Nuss group (88.2 hours) when compared to the Ravitch group (67 hours) $(p=0.0002)$ [23]. Antonoff et al. reported that perioperative pain differed among the Nuss and Ravitch groups, with $100 \%$ and $50 \%$ of patients in these groups requiring epidural analgesia, respectively (statistical significance not reported) [46]. Interestingly, Inge et al. reported a similar use of prescription analgesics regardless of the surgical technique used, with greater than $75 \%$ of all patients requiring narcotics, ketorolac, and methocarbamolfor a period of less than 2 weeks [54]. No patient received epidural analgesia, regardless of the repair technique selected [54-59]. Meta-analysis on postoperative cosmetic satisfaction is yet to be performed, though this represents a challenge due to variations in measurement techniques and metrics utilized [33].

Correction of pectus deformities may serve to reduce the incidence of cardiovascular and pulmonary complications secondary to chest wall malformation, while simultaneously improving body image, psychosocial development, and exercise tolerance in affected patients. The Ravitch and Nuss procedures remain the most frequently employed methods of treatment, with their comparative complication rates showing no statistical difference. However, the cosmetic advantages and minimally invasive nature of the Nuss procedure make it a more attractive option when compared to other pectus deformity repair methods. Though management using the $3 \mathrm{MP}$, 
dynamic compression bracing, and vacuum bell represent appealing treatment modalities, a definitive evidencebased conclusion has not yet been reached with regards to the cost-effectiveness, long-term patient satisfaction, overall complication rates, and deformity recurrence rates of these newer therapies, and whether they are capable of generating patient outcomes equal or superior to those observed in patients undergoing the Ravitch and Nuss procedures.

\section{REFERENCES}

[1] Chung, C.S. and Myrianthopoulos, N.C. (1975) Factors affecting risks of congenital malformations. I. Analysis of epidemiologic factors in congenital malformations. Report from the collaborative perinatal project. Birth Defects Original Article Series, 11, 1-22.

[2] Blanco, F., Elliott, S. and Sandler, A. (2011) Management of congenital chest wall deformities. Seminars in Plastic Surgery, 25, 107-116. doi:10.1055/s-0031-1275177

[3] Coran, A.G., Adzick, N.S., Krummel, T.M., Laberge, J.M., Shamberger, R.C. and Caldamone, A.A. (2012) Pediatric Surgery. 7th Edition, Elsevier Saunders, Amsterdam, 779-796.

[4] Fonkalsrud, E.W. (2003) Current management of pectus excavatum. World Journal of Surgery, 27, 502-508. doi:10.1007/s00268-003-7025-5

[5] Kotzot, D. and Schwabegger, A.H. (2009) Etiology of chest wall deformities-A genetic review for the treating physician. Journal of Pediatric Surgery, 44, 20042011. doi:10.1016/j.jpedsurg.2009.07.029

[6] Romano, A.A., Allanson, J.E., Dahlgren, J., Gelb, B.D., Hall, B., Pierpont, M.E., et al. (2010) Noonan syndrome: Clinical features, diagnosis, and management guidelines. Pediatrics, 126, 746-759.

doi:10.1542/peds.2009-3207

[7] Creswick, H.A., Stacey, M.W., Kelly Jr., R.E., Gustin, T., Nuss, D., Harvey, H., et al. (2006) Family study of the inheritance of pectus excavatum. Journal of Pediatric Surgery, 41, 1699-1703.

doi:10.1016/j.jpedsurg.2006.05.071

[8] Chu, Z., Yu, J., Yang, Z., Peng, L., Bai, H. and Li, X. (2010) Correlation between sternal depression and cardiac rotation in pectus excavatum: Evaluation with helical CT. American Journal of Roentgenology, 195, W76-W80. doi:10.2214/AJR.09.3199

[9] Chin, E.F. (1957) Surgery of funnel chest and congenital sternal prominence. The British Journal of Surgery, 44, 360-376. doi:10.1002/bjs.18004418607

[10] Iida, H. (2010) Surgical repair of pectus excavatum. General Thoracic and Cardiovascular Surgery, 58, 55-61. doi:10.1007/s11748-009-0521-2

[11] Morshuis, W., Folgering, H., Barentsz, J., van Lier, H. and Lacquet, L. (1994) Pulmonary function before surgery for pectus excavatum and at long-term follow-up. Chest, 105, 1646-1652. doi:10.1378/chest.105.6.1646
[12] Jaroszewski, D., Notrica, D., McMahon, L., Steidley, D.E. and Deschamps, C. (2010) Current management of pectus excavatum: A review and update of therapy and treatment recommendations. Journal of the American Board of Family Medicine, 23, 230-239. doi:10.3122/jabfm.2010.02.090234

[13] Saint-Mezard, G., Chanudet, X., Duret, J.C., Larrue, J., Bonnet, J. and Bricaud, H. (1986) Mitral valve prolapse and pectus excavatum: Expressions of connective tissue dystrophy? Archives des Maladies du Coeuret des Vaisseaux, 79, 431-434.

[14] Shamberger, R.C. (1998) Congenital chest wall deformities. In: O’Neill, J., Rowe, M.I. and Grosfeld, J.L., Eds., Pediatric Surgery, 5th Edition, Mosby, St. Louis, 787.

[15] Martinez-Ferro, M., Fraire, C. and Bernard, S. (2008) Dynamic compression system for the correction of pectus carinatum. Seminars in Pediatric Surgery, 17, 194-200. doi:10.1053/j.sempedsurg.2008.03.008

[16] Nuchtern, J.G. and Mayer, O.H. (2012) Pectus carinatum. In: Redding, G., Ed., UpToDate, UpToDate, Waltham.

[17] Brigato, R.R., Campos, J.R.M., Jatene, F.B., Moreira, L.F.P. and Rebeis, E.B. (2008) Pectus excavatum: Evaluation of Nuss technique by objective methods. Interactive Cardiovascular and Thoracic Surgery, 7, 1084-1088. doi:10.1510/icvts.2008.184580

[18] Haller, J.A., Kramer, S.S. and Lietman, S.A. (1987) Use of CT scans in selection of patients for pectus excavatum surgery: A preliminary report. Journal of Pediatric Surgery, 22, 904-906. doi:10.1016/S0022-3468(87)80585-7

[19] Schwabegger, A.H. (2011) Congenital thoracic wall deformities: Diagnosis, therapy and current developments. Springer-Verlag/Wien, New York, 79-80. doi:10.1007/978-3-211-99138-1

[20] Ji, Y., Wenying, L., Chen, S., Xu, B., Tang, Y., Wang, X., Yang, G. and Cao, L. (2011) Assessment of psychosocial functioning and its risk factors in children with pectus excavatum. Health and Quality of Life Outcomes, 9, 1-8. doi:10.1186/1477-7525-9-28

[21] Kelly, R.E. (2008) Pectus excavatum: Historical background, clinical picture, preoperative evaluation and criteria for operation. Seminars in Pediatric Surgery, 17, 181-193. doi:10.1053/j.sempedsurg.2008.03.002

[22] Kelly Jr., R.E., Cash, T.F., Shamberger, R.C., Mitchell, K.K., Mellins, R.B., Lawson, M.L., et al. (2008) Surgical repair of pectus excavatum markedly improves body image and perceived ability for physical activity: Multicenter study. Pediatrics, 122, 1218-1222. doi:10.1542/peds.2007-2723

[23] Lam, M.W., Klassen, A.F., Montgomery, C.J., LeBlanc, J.G. and Skarsgard, E.D. (2008) Quality-of-life outcomes after surgical correction of pectus excavatum: A comparison of the Ravitch and Nuss procedures. Journal of Pediatric Surgery, 43, 819-825. doi:10.1016/j.jpedsurg.2007.12.020

[24] Krasopoulos, G., Dusmet, M., Ladas, G. and Goldstraw, P. (2006) Nuss procedure improves the quality of life in young male adults with pectus excavatum deformity. European Journal Cardio-Thoracic Surgery, 29, 1-5. 
doi:10.1016/j.ejcts.2005.09.018

[25] Steinmann, C., Krille, S., Mueller, A., Weber, P., Reingruber, B. and Martin, A. (2011) Pectus excavatum and pectus carinatum patients suffer from lower quality of life and impaired body image: A control group comparison of psychological characteristics prior to surgical correction. European Journal of Cardiothoracic Surgery, 40, 11381145.

[26] Ebstein, W. (1882) Ueber die trichterbrust. Deutsches Architektur, 30, 411.

[27] Meade, R.H. (1961) A history of thoracic surgery. Thomas, Springfield.

[28] Sauerbruch, F. (1920) Die chirurgie der brustorgane. Springer, Berlin.

[29] Goretsky, M.J., Kelly Jr., R.E., Croitoru, D. and Nuss, D. (2004) Chest wall anomalies: Pectus excavatum and pectus carinatum. Adolescent Medicine, 15, 455-471. doi:10.1016/j.admecli.2004.06.002

[30] Sauerbruch, F. (1931) Operative beseitigung der angeborenentrichterbrust. Deutsche Zeitschrift furChirurgie, 234, 760. doi:10.1007/BF02797645

[31] Brown, A.L. and Cook, O. (1951) Funnel chest (pectus excavatum) in infancy and adult life. California Medicine, 74, 174-178.

[32] Krueger, T., Chassot, P.G., Christodoulou, M., Cheng, C., Ris, H.B. and Magnusson L. (2010) Cardiac function assessed by transesophageal echocardiography during pectus excavatum repair. Annals of Thoracic Surgery, 89, 240-244. doi:10.1016/j.athoracsur.2009.06.126

[33] Nasr, A., Fecteau, A. and Wales, P.W. (2010) Comparison of the Nuss and Ravitch procedure for pectus excavatum repair: A meta-analysis. Journal of Pediatric Surgery, 45, 880-886. doi:10.1016/j.jpedsurg.2010.02.012

[34] Ravitch, M.M. (1949) The operative treatment of pectus excavatum. Annals of Surgery, 129, 429-444. doi:10.1097/00000658-194904000-00002

[35] Luu, T.D., Kogon, B.E., Force, S.D., Mansour, K.A. and Miller, D.L. (2009) Surgery for recurrent pectus deformities. The Annals of Thoracic Surgery, 88, 1627-1631. doi:10.1016/j.athoracsur.2009.06.008

[36] Colombani, P.M. (2003) Recurrent chest wall anomalies. Seminars in Pediatric Surgery, 12, 94-99. doi:10.1016/S1055-8586(02)00018-5

[37] Boehm, R.A., Muensterer, O.J. and Till, H. (2004) Comparing minimally invasive funnel chest repair versus the conventional technique: An outcome analysis in children. Plastic and Reconstructive Surgery, 114, 668-673. doi:10.1097/01.PRS.0000130938.87402.B0

[38] Fonkalsrud, E.W., Dunn, J.C.Y. and Atkinson, J.B. (2000) Repair of pectus excavatum deformities: 30 years of experience with 375 patients. Annals of Surgery, 231, 443448. doi:10.1097/00000658-200003000-00019

[39] Chen, C.H., Liu, H.C., Hung, T.T. and Chen, C.H. (2010) Restrictive chest wall deformity as a complication of surgical repair for pectus excavatum. The Annals of Thoracic Surgery, 89, 599-601.

doi:10.1016/j.athoracsur.2009.06.091
[40] Haje, S.A. and Bowen, J.R. (1992) Preliminary results of orthotic treatment of pectus deformities in children and adolescents. Journal of Pediatric Orthopedics, 12, 795800. doi:10.1097/01241398-199211000-00018

[41] Kim, D.H., Hwang, J.J., Lee, M.K., Lee, D.Y. and Paik, H.C. (2005) Analysis of the Nuss procedure for excavatum in different age groups. The Annals of Thoracic Surgery, 80, 1073-1077. doi:10.1016/j.athoracsur.2005.03.070

[42] Nuss, D., Kelly Jr., R.E., Croitoru, D.P. and Katz, M.E. (1998) A 10-year review of a minimally invasive technique for the correction of pectus excavatum. Journal of Pediatrics, 33, 545-552.

[43] Nuss, D., Kelly Jr., R.E., Croitoru, D.P. and Swoveland, B. (1998) Repair of pectus excavatum. Pediatric Endosurgery and Innovative Techniques, 2, 205-221. doi:10.1089/pei.1998.2.205

[44] Haecker, F.-M. and Mayr, J. (2006) The vacuum bell for treatment of pectus excavatum: An alternative to surgical correction? European Journal of Cardiothoracic Surgery, 29, 557-561. doi:10.1016/j.ejcts.2006.01.025

[45] Fonkalsrud, E.W., Beanes, S., Hebra, A., Adamson, W. and Tagge E. (2002) Comparison of minimally invasive and modified Ravitch pectus excavatum repair. Journal of Pediatric Surgery, 37, 413-417. doi:10.1053/jpsu.2002.30852

[46] Antonoff, M.B., Erickson, A.E., Hess, D.J., Acton, R.D. and Saltzman, D.A. (2009) When patients choose: Comparison of Nuss, Ravitch, and Leonard procedures for primary repair of pectus excavatum. Journal of Pediatric Surgery, 44, 1113-1118. doi:10.1016/j.jpedsurg.2009.02.017

[47] Castellani, C., Windhaber, J., Schober, P.H. and Hoellworth M.E. (2010) Exercise performance testing in patients with pectus excavatum before and after Nuss procedure. Pediatric Surgery International, 26, 659-663. doi:10.1007/s00383-010-2627-0

[48] Ohno, K., Nakamura, T., Azume, T., Yamada, H., Hayashi, H. and Masahata, K. (2009) Modification of the Nuss procedure for pectus excavatum to prevent cardiac perforation. Journal of Pediatric Surgery, 44, 2426-2430. doi:10.1016/j.jpedsurg.2009.09.006

[49] Nagasao, T., Noguchi, M., Miyamoto, J., Jiang, H., Ding, W., Shimizu, Y., et al. (2010) Dynamic effects of the Nuss procedure on the spine in asymmetric pectus excavatum. The Journal of Thoracic and Cardiovascular Surgery, 140, 1294-1299. doi:10.1016/j.jtcvs.2010.06.025

[50] Kelly Jr., R.E., Shamberger, R.C. and Mellins, R.B. (2007) Prospective multicenter study of surgical correction of pectus excavatum: Design, perioperative complications, pain, and baseline pulmonary function facilitated by internet-based data collection. Journal of the American College of Surgeons, 205, 205-216. doi:10.1016/j.jamcollsurg.2007.03.027

[51] Harrison, M.R., Gonzales, K.D., Bratton, B.J., Christensen D., Curran, P.F., Fechter, R. and Hirose, S. (2012) Magnetic mini-mover procedure for pectus excavatum III: Safety and efficacy in a food and drug administrationsponsored clinical trial. Journal of Pediatric Surgery, 47, 
154-159. doi:10.1016/j.jpedsurg.2011.10.039

[52] Haller Jr., J.A., Scherer, L.R., Turner, C.S. and Colombani P.M. (1989) Evolving management of pectus excavatum based on a single institutional experience of 664 patients. Annals of Surgery, 209, 578-582. doi:10.1097/00000658-198905000-00010

[53] Kelly Jr., R.E., Goretsky, M.J., Obermeyer, R., Kuhn, M.A., Redlinger, R., Haney, T.S., Moskowitz, A. and Nuss, D. (2010) Twenty-one years of experience with minimally invasive repair of pectus excavatum by the Nuss procedure in 1215 patients. Annals of Surgery, 252, 10721081. doi:10.1097/SLA.0b013e3181 effdce

[54] Inge, T.H., Owings, E., Blewett, C.J., Baldwin, C.E., Cain, W.S., Hardin, W. and Georgeson, K.E. (2003) Reduced hospitalization cost for patients with pectus excavatum treated using minimally invasive surgery. Surgical Endoscopy, 17, 1609-1613. doi:10.1007/s00464-002-8767-0

[55] Wang, L.S., Kuo, K.T. and Wang, H.W. (2005) A novel surgical correction through a small transverse incision for pectus excavatum. Annals of Thoracic Surgery, 80, 19511954. doi:10.1016/j.athoracsur.2004.05.029

[56] Nuss, D. and Kelly Jr., R.E. (2010) Indications and technique of Nuss procedure for pectus excavatum. Thoracic Surgery Clinics, 20, 583-597. doi:10.1016/j.thorsurg.2010.07.002

[57] Mansour, K.A., Thourani, V.H., Odessey, E.A., Durham, M.M., Miller Jr., J.I. and Miller, D.L. (2003) Thirty-year experience with repair of pectus deformities in adults. Annals of Thoracic Surgery, 76, 391-395. doi:10.1016/S0003-4975(03)00441-7

[58] Hellwig and Ansgar, (2012) Pectus1.jpg. Digital image. Wikimedia Commons, Wikimedia Foundation. http://commons.wikimedia.org/wiki/File:Pectus1.jpg

[59] Jprealini (2012) Pectus carinatum Mmf.JPG. Digital image. Wikimedia Commons, Wikimedia Foundation. http://commons.wikimedia.org/wiki/File:Pectus_carinatu $\underline{\mathrm{m} m \mathrm{mmf} . J P G}$ 